\title{
Assessing foliar chlorophyll contents with the SPAD-502 chlorophyll meter: a calibration test with thirteen tree species of tropical rainforest in French Guiana
}

\author{
Sabrina COSTE ${ }^{1}$, Christopher BARAlOTO ${ }^{1}$, Céline LEROY $^{2}$, Éric MARCON $^{3}$, Amélie RenAUD $^{3}$, \\ Andrew D. RICHARDSON ${ }^{4}$, Jean-Christophe RoGGY ${ }^{1}$, Heidy ScHIMANN ${ }^{1}$, Johan UdDLING ${ }^{5}$, \\ Bruno HÉRAULT ${ }^{6 *}$ \\ ${ }^{1}$ INRA - Unité Mixte de Recherche Écologie des Forêts de Guyane, Kourou, France \\ ${ }^{2}$ CNRS - Unité Mixte de Recherche Écologie des Forêts de Guyane, Kourou, France \\ ${ }^{3}$ AgroParisTech-ENGREF- Unité Mixte de Recherche Écologie des Forêts de Guyane, Kourou, France \\ ${ }^{4}$ Harvard University, Department of Organismic and Evolutionary Biology, Harvard University Herbaria, \\ 22 Divinity Avenue Cambridge, MA 02138, USA \\ ${ }^{5}$ University of Gothenburg, Department of Plant and Environmental Sciences, Göteborg, Sweden \\ ${ }^{6}$ Université des Antilles et de la Guyane, Unité Mixte de Recherche Ecologie des Forêts de Guyane, Kourou, France
}

(Received 27 March 2009; accepted 21 December 2009)

Keywords:

chlorophyll estimate /

model calibration /

homographic functions /

neotropical trees

\begin{abstract}
- Chlorophyll meters such as the SPAD-502 offer a simple, inexpensive and rapid method to estimate foliar chlorophyll content. However, values provided by SPAD-502 are unitless and require empirical calibrations between SPAD units and extracted chlorophyll values.

- Leaves of 13 tree species from the tropical rain forest in French Guiana were sampled to select the most appropriate calibration model among the often-used linear, polynomial and exponential models, in addition to a novel homographic model that has a natural asymptote.

- The homographic model best accurately predicted total chlorophyll content $\left(\mu \mathrm{g} \mathrm{cm}^{-2}\right)$ from SPAD units $\left(R^{2}=0.89\right)$. Interspecific differences in the homographic model parameters explain less than $7 \%$ of the variation in chlorophyll content in our data set.

- The utility of the general homographic model for a variety of research and management applications clearly outweighs the slight loss of model accuracy due to the abandon of the species' effect.
\end{abstract}

\section{INTRODUCTION}

Traditional extraction-based methods of measuring chlorophyll content in forest trees are lengthy and expensive. Nondestructive methods have therefore been developed and inexpensive optical chlorophyll meters, such as the SPAD-502 (Konica Minolta, Osaka, Japan), are frequently used (Hawkins et al., 2009; Marenco et al., 2009; Pinkard et al., 2006; Uddling et al., 2007). Although these meters are portable and suitable for field use, they remain underutilised in forest science, perhaps because SPAD units are difficult to interpret. Indeed, SPAD value depends not only on chlorophyll content but also on other aspects of leaf optics, which may be influenced by various environmental and biological factors (Manetas et al., 1998; Markwell et al., 1995). The establishment of reference curves relating SPAD-unit and total foliar chlorophyll un-

* Corresponding author: bruno.herault@ecofog.gf der controlled environmental conditions is therefore a high priority.

To our knowledge, apart from the recent work of Marenco et al. (2009), research evaluating the use of SPAD units to estimate chlorophyll content in trees has been limited to certain fruit trees (e.g. Schaper and Chacko, 1991) or ornamental species (Pinkard et al., 2006; Richardson et al., 2002; Uddling et al., 2007). More generally, the current literature suffers from at least two limitations. First, the SPAD meter is unable to measure very low transmittances. However, all studies to date have based the calibration model on either exponential or, more often, polynomial relationships with no saturation level at high chlorophyll content. To correct this, we propose a new calibration model based on a homographic function that has a natural asymptote. A second limitation is the use of different calibration models in different studies which complicates rigorous comparisons of calibrations among a large panel of species. Tropical trees present an opportune system to study 
Table I. List of the studied tree species and their systematic position. Mean values $( \pm 95 \%$ confidence interval) of leaf mass-per-area (LMA, $\mathrm{g} \mathrm{m}^{-2}$ ) and leaf thickness $(\mu \mathrm{m})$ for leaves sampled under $20 \%$ of full irradiance are displayed. The number of samples $(n)$, the parameters of the homographic models $\left(\alpha\right.$ and $\beta$ ) and the coefficient of determination $\left(R^{2}\right)$ are indicated for the 13 studied species.

\begin{tabular}{|c|c|c|c|c|c|c|c|}
\hline \multirow{2}{*}{ Species name } & \multirow{2}{*}{ Family name } & \multicolumn{2}{|c|}{ Leaf structural characteristics } & \multicolumn{4}{|c|}{ Homographic model } \\
\hline & & LMA $\left(\mathrm{g} \mathrm{m}^{-2}\right)$ & Thickness $(\mu \mathrm{m})$ & $n$ & $\alpha$ & $\beta$ & $R^{2}$ \\
\hline Amanoa guianensis J.B. Aublet & Euphorbiaceae & $102 \pm 7.9$ & $313 \pm 15$ & 30 & $124.1 \pm 13.7$ & $158.4 \pm 10.6$ & 0.98 \\
\hline Bagassa guianensis J.B. Aublet & Moraceae & $38.2 \pm 1.8$ & $165 \pm 12$ & 30 & $147.6 \pm 39.4$ & $170.0 \pm 35.8$ & 0.97 \\
\hline Carapa procera A.P. de Candolle & Meliaceae & $81.8 \pm 4.4$ & $220 \pm 5$ & 30 & $147.6 \pm 24.5$ & $193.7 \pm 22.9$ & 0.98 \\
\hline Cecropia obtusa Trécul. & Cecropiaceae & $56.4 \pm 6.6$ & $254 \pm 30$ & 29 & $49.6 \pm 10.0$ & $88.2 \pm 8.8$ & 0.92 \\
\hline Eperua falcata J.B. Aublet & Caesalpiniaceae & $67.4 \pm 4.7$ & $158 \pm 4$ & 32 & $205.5 \pm 38.5$ & $299.2 \pm 45.8$ & 0.78 \\
\hline Hymenaea courbaril Linnaeus & Caesalpiniaceae & $59.8 \pm 6.4$ & $115 \pm 8$ & 34 & $195.0 \pm 77.2$ & $201.0 \pm 61.6$ & 0.91 \\
\hline Inga thibaudiana D.C. & Mimosaceae & $75.7 \pm 9.3$ & $167 \pm 18$ & 34 & $331.2 \pm 108.5$ & $274.1 \pm 70.4$ & 0.94 \\
\hline Pouteria sp. J.B. Aublet & Sapotaceae & $119 \pm 11$ & $289 \pm 22$ & 28 & $133.0 \pm 51.2$ & $150.9 \pm 29.1$ & 0.92 \\
\hline Protium opacum Swart & Burseraceae & $92.0 \pm 7.6$ & $228 \pm 20$ & 31 & $165.4 \pm 70.4$ & $197.6 \pm 52.6$ & 0.94 \\
\hline Sextonia rubra $(\mathrm{Mez})$ van der Weff & Lauraceae & $73.9 \pm 7.4$ & $259 \pm 12$ & 30 & $169.9 \pm 20.2$ & $198.6 \pm 17.2$ & 0.99 \\
\hline Symphonia globulifera Linnaeus f. & Clusiaceae & $71.2 \pm 7.4$ & $314 \pm 21$ & 30 & $154.1 \pm 35.8$ & $197.6 \pm 31.9$ & 0.98 \\
\hline Tachigali melinonii (Harms) Barneby & Caesalpiniaceae & $59.0 \pm 5.6$ & $121 \pm 8$ & 23 & $164.7 \pm 33.2$ & $158.3 \pm 23.0$ & 0.97 \\
\hline Voиасароиа атеricana J.B. Aublet & Caesalpiniaceae & $49.2 \pm 4.4$ & $118 \pm 7$ & 30 & $69.2 \pm 60.5$ & $112.8 \pm 57.9$ & 0.91 \\
\hline
\end{tabular}

the potential for differential SPAD-chlorophyll relationships among species because they include a broad gradient of leaf types with different anatomical and physiological properties (Coste et al., 2005; Rozendaal et al., 2006).

In this study, we apply a novel homographic function to a data set of SPAD and chlorophyll measures of 13 tropical tree species representing a three-fold gradient in specific leaf area, and chlorophyll content ranging from $\approx 0$ to $\approx 150 \mu \mathrm{g} / \mathrm{cm}^{2}$ total chlorophyll (Tab. I). In particular, we address the following questions: (1) is a homographic model appropriate for calibration of relationships between SPAD unit and chlorophyll content? (2) How does a general model perform relative to multiple species-specific models?

\section{MATERIAL AND METHODS}

\subsection{Plant material}

Our study was conducted in a greenhouse at Kourou, French Guiana ( $5^{\circ} 10^{\prime} \mathrm{N}, 52^{\circ} 40^{\prime} \mathrm{W}$ ) between May and July 2005. Thirteen tropical rainforest tree species, with various light requirements, were selected to cover a broad range of leaf structural characteristics (Tab. I). Seeds or saplings from at least five parent trees per species were collected from March to July 2003. They were grown in the greenhouse from December 2003 in $30 \mathrm{~L}$ pots with a 1:2(v/v) mixture of a brown ferralitic clay soil and a white sand of podzolic origin. During July 2004, all pots received 40 g slow-release complete fertilizer (Multicote 4, 17/17/17 N/P/K). Seedlings were irrigated daily with drip irrigation in order to maintain soil at field capacity $\left(0.25 \mathrm{~m}^{3} \mathrm{~m}^{-3}\right)$.

Shading nets were used to establish treatments that represent the range of light conditions experienced by seedlings in the lowland forests of French Guiana (Baraloto et al., 2005). The three irradiance treatments corresponded to 5, 10 and $20 \%$ of full sun, as recorded during $3 \mathrm{~d}$-long measurement campaigns with inter-calibrated quantumsensors for photosynthetically active radiation (PAR CBE 80 Solems,
Palaiseau, France) compared to an external sensor. Ten replicates per species were grown under each irradiance level.

\subsection{Sampling}

For each studied species, approximately 30 leaf samples were selected to cover the range of SPAD units exhibited across the light gradient. A sample consisted of a $0.78 \mathrm{~cm}^{2}$ leaf disk. Three measurements using a SPAD-502 (Konica-Minolta, Osaka, Japan) were taken from the leaf disk and disk fresh weight $(\mathrm{mg})$ was recorded. Immediately after measurements, samples were immersed in DMSO (dimethylsulfoxide) and kept in the dark.

\subsection{Chlorophyll extraction}

We used the DMSO extraction technique of Hiscox and Israelstam (1979). Samples were incubated at $65^{\circ} \mathrm{C}$ until leaf disks were completely colourless and the DMSO had turned green. Absorbance of the DMSO-chlorophyll extractions was then measured at $647 \mathrm{~nm}$ and $664 \mathrm{~nm}$, relative to a DMSO blank, using a spectrophotometer (Jenway 6305 UV/Vis Spectrophotometer, Jenway, Essex, UK). The spectrophotometer was previously calibrated using commercial solutions of spinach chlorophylls a and b (BioChemika 10865 and 25740 , respectively). Calibration procedure provided the Equations (1) and (2).

$$
\begin{aligned}
& C h l_{\mathrm{a}}\left(\mathrm{mg} \mathrm{m}^{-1}\right)=22 D O_{664}-9.1 D O_{647} \\
& C h l_{\mathrm{b}}\left(\mathrm{mg} \mathrm{ml}^{-1}\right)=29.5 D O_{647}-10.2 D O_{664}
\end{aligned}
$$

with $\mathrm{Chl}_{\mathrm{a}}$ and $\mathrm{Chl}_{\mathrm{b}}$, the total content of chlorophyll a and b respectively; $\mathrm{DO}_{664}$ and $\mathrm{DO}_{647}$, the optical densities read for wavelengths of $664 \mathrm{~nm}$ and $647 \mathrm{~nm}$ respectively. 


\subsection{Data analysis}

We first calibrate an empirical relationship between SPAD unit and chlorophyll content for all 13 species together. Throughout the literature, three models have been used: linear, polynomial, or exponential. We developed a new homographic model (Eq. (3)) and tested which one out of these four models fit our data best.

$$
C h l_{\mathrm{i}}=\left(\alpha S P A D_{\mathrm{i}} /\left(\beta-S P A D_{\mathrm{i}}\right)\right)+\epsilon_{i}
$$

where Chl is the total content in chlorophyll ( $\mathrm{a}$ and $\mathrm{b}$ ) of the sample $\mathrm{i}$, SPAD is the unitless reading from the SPAD-502 meter, $\alpha$ and $\beta$ the fitted model parameters, and $\varepsilon$ the model residuals.

The four competitive models (linear, polynomial, exponential or homographic) were compared for:

(1) their accuracy (i.e. their ability to minimize the residual variance) by using the Akaike Information Criterion (AIC);

(2) their robustness (i.e. their ability to predict an unseen data set) using a cross-validation technique.

We randomly split the data set into training and testing data sets of equal sample size. Each model was calibrated on the training data set and the values of the testing data set were then predicted using this calibration. Robustness was estimated using the coefficient of determination $\left(R^{2}\right)$ and root mean square error of prediction (RMSEP) between predicted and observed values of the testing set. The procedure was repeated 1000 times.

The species' effect was investigated by comparing AIC values for the general and species-specific model parameterization, with the one having the lowest AIC being the best. A residual bootstrap procedure (Efron and Tibshirani, 1993) was used to estimate the variance of the fitted parameters for each model.

Finally, to test the performance of our newly-calibrated model against other published models calibrated on different species, we compared these competing models in two ways. First, we tested the ability of the published models to predict our data. Second, we tested the ability of our newly-calibrated model to predict some raw data. Model performance was assessed using the $R^{2}$ and the RMSEP.

\section{RESULTS}

The relationship between total chlorophyll content and SPAD units was curvilinear (Fig. 1). The linear model, displaying the highest AIC value, was therefore the least accurate (Tab. II). Among the other models, the homographic model minimized the residual variance (Tab. II), displayed the lowest root mean square error of prediction $(R M S E P=201)$ and the higher $R^{2}\left(R^{2}=0.89\right)$. Among the 11 different models from the literature applied to our data set, the new homographic model best predicts our data (Tab. III). The RMSEP were generally lowest for models calibrated on tropical trees (Mangifera indica, Eucalyptus spp.). The performance of our newly-calibrated general homographic model to predict independent data sets gathered on other species is similar to the original models developed specifically for these species (Appendix $\left.^{1} 1\right)$.

\footnotetext{
${ }^{1}$ Appendices are available on line only at www.afs-journal.org.
}

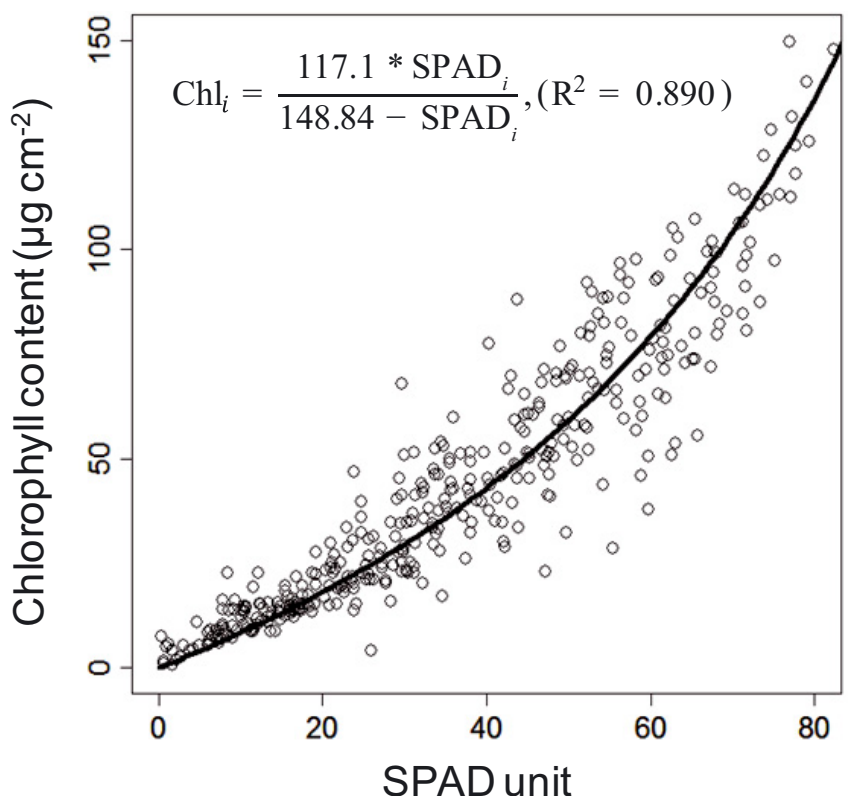

Figure 1. Relationships between leaf chlorophyll content and SPAD units for 13 neotropical trees. Homographic model was parameterized on the whole data set $(n=391$ samples from 13 neotropical tree species). Equation of the homographic model and coefficient of determination $\left(R^{2}\right)$ are displayed.

When the effect of species was taken into account, the AIC of the relationship between total chlorophyll contents and SPAD units decreased from 3029 to 2661 . Among the 13 studied neotropical tree species, $\alpha$ ranged from 50 to 331 and $\beta$ from 88 to 299 (Tab. I). All species-specific models had coefficients of determination $\left(R^{2}\right)$ above 0.9, except Eperua falcata $\left(R^{2}=0.78\right)$. Whereas the general homographic model obtained an $R^{2}$ value of 0.89 (Fig. 1), adding a species-effect increased the $R^{2}$ value to 0.96 .

\section{DISCUSSION}

Linear regressions resulted in a higher Akaike Information Criterion highlighting lower predictability in the high SPAD range as has been shown by Uddling et al. (2007). Indeed, at least 11 out of 13 tropical trees (omitting Inga thibaudiana and Eperua falcata) had a pronounced non-linear SPADchlorophyll relationship (Appendix ${ }^{1}$ 2). Several methods have been used to model such a curvilinear behaviour. In the literature, most authors employ second-order polynomials (Monje and Bugbee, 1992; Richardson et al., 2002) or exponential equations (Uddling et al., 2007). We introduced a new model that provided more readily interpretable parameters. Moreover, this new model best fit our data, was the most robust (Tab. II) and we were able to properly estimate the asymptotic value $(\beta)$ above which the SPAD-502 does not work because of a high light absorption level. Our choice of a homographic model with no intercept was first based on a close examination of our data and on its fewer parameter number. To our knowledge, most published models have used an intercept (see 
Table II. Comparison of the accuracy and the robustness of 4 competitive general models developed to predict chlorophyll content (Chl) with a SPAD-502. Accuracy was estimated using the Akaike Information Criterion (AIC). Robustness was estimated using both the coefficient of determination $R^{2}$ and the Root Mean Square Error of Prediction (RMSEP) throughout a cross-validation procedure.

\begin{tabular}{|c|c|c|c|c|c|c|c|c|c|}
\hline Model & $\alpha$ & $\beta$ & AIC & $\operatorname{Min} R^{2}$ & Mean $R^{2}$ & $\operatorname{Max} R^{2}$ & Min RMSEP & Mean RMSEP & Max RMSEP \\
\hline \multicolumn{10}{|l|}{ Linear } \\
\hline $\begin{array}{l}C h l_{\mathrm{i}}=\alpha * S P A D_{\mathrm{i}} \\
\text { Polynomial }\end{array}$ & $1.310 \pm 0.009$ & - & 3215.9 & 0.8057 & 0.8454 & 0.8868 & 157.7 & 207.2 & 251.3 \\
\hline $\begin{array}{l}C h l_{\mathrm{i}}=\alpha * S P A D_{\mathrm{i}}+\beta * S P A D_{\mathrm{i}}^{2} \\
\text { Exponential }\end{array}$ & $0.664 \pm 0.040$ & $0.012 \pm 0.001$ & 3075.3 & 0.8485 & 0.8794 & 0.9174 & 141.4 & 175.0 & 208.8 \\
\hline $\begin{array}{l}C h l_{\mathrm{i}}=\alpha\left(e^{\beta * S P A D_{\mathrm{i}}}-1\right) \\
\text { Homographic }\end{array}$ & $0.018 \pm 0.001$ & $42.85 \pm 4.48$ & 3049.2 & 0.8554 & 0.8853 & 0.9201 & 139.1 & 170.7 & 204.3 \\
\hline$C h l_{\mathrm{i}}=\left(\alpha * S P A D_{\mathrm{i}} /\left(\beta-S P A D_{\mathrm{i}}\right)\right)$ & $117.10 \pm 6.53$ & $148.84 \pm 8.69$ & 3029.7 & 0.8598 & 0.8899 & 0.9211 & 137.3 & 164.9 & 201.4 \\
\hline
\end{tabular}

Table III. Comparison of the ability of 11 published models, linking total chlorophyll content (units are given for each model; $Y$ ) to Spad units $(X)$, to predict our 13 neotropical trees data set. Relative performance of models was assessed using Root Mean Square Error of Prediction (RMSEP).

\begin{tabular}{|c|c|c|c|c|}
\hline Species & Reference & Model & Unit & RMSEP \\
\hline Betula papyrifera Marsh. & Richardson et al. (2002) & $Y=5,52 \mathrm{E}-04+4.04 \mathrm{E}-04 * \mathrm{X}+1.25 \mathrm{E}-05$ & $* \mathrm{X}^{2} \mathrm{mg} \mathrm{cm}^{-2}$ & 14.67 \\
\hline Betula pendula Roth & Uddling et al. (2007) & $Y=0.0641 * \exp (0.0467 \mathrm{X})$ & $\mathrm{g} \mathrm{m}^{-2}$ & 35.93 \\
\hline Eucalyptus globules Labill. & Pinkard et al. (2006) & $Y=\exp (-8.79+2.08 * \ln (\mathrm{X}))$ & $\mu \mathrm{g} \mathrm{mm}^{-2}$ & 15.38 \\
\hline Eucalyptus nitens (H. Deane \& Maiden) Maiden & Pinkard et al. (2006) & $Y=\exp (-8.55+0.97 * \ln (\mathrm{X}))$ & $\mu \mathrm{g} \mathrm{mm} \mathrm{m}^{-2}$ & 17.74 \\
\hline Mangifera indica $\mathrm{L}$. & Schaper and Chacko (1991) & $Y=-5.4+11.1 * \mathrm{X}$ & $\mathrm{mg} \mathrm{m}^{-2}$ & 17.08 \\
\hline Malus domestica Borkh & Campbell et al. (1990) & $Y=-83+2.37 * X$ & $\mu \mathrm{g} \mathrm{cm}^{-2}$ & 47.86 \\
\hline Oriza sativa $\mathrm{L}$. & Monje and Bugbee (1992) & $Y=1.034+0.308 * \mathrm{X}+0.11 * \mathrm{X}^{2}$ & $\mathrm{mg} \mathrm{m}^{-2}$ & 30.31 \\
\hline Solanum tuberosum $\mathrm{L}$. & Uddling et al. (2007) & $Y=0.0913 * \exp (0.0415 * \mathrm{X})$ & $\mathrm{g} \mathrm{m}^{-2}$ & 33.60 \\
\hline Triticum aestivum $\mathrm{L}$. & Uddling et al. (2007) & $Y=0.0599 * \exp (0.0493 * \mathrm{X})$ & $\mathrm{g} \mathrm{m}^{-2}$ & 46.18 \\
\hline Vigna unguiculata (L.) Walp. & Murillo-Amador et al. (2004) & $Y=-2.79+0.88 * \mathrm{X}$ & $\mu \mathrm{g} \mathrm{cm}^{-2}$ & 24.98 \\
\hline 6 neotropical trees & Marenco et al. (2009) & $Y=0.53 * \exp (0.0364 * \mathrm{X})$ & $\mathrm{mg} \mathrm{m}^{-2}$ & 24.21 \\
\hline 13 neotropical trees & Present study & $Y=117.1 * \mathrm{X} /(148.84-\mathrm{X})$ & $\mu \mathrm{g} \mathrm{cm}^{-2}$ & 11.59 \\
\hline
\end{tabular}

Tab. III). Markwell et al. (1995) justified such an intercept by citing a stronger absorbance of chlorophyll $b$ than of chlorophyll a at $650 \mathrm{~nm}$, but this statement was not supported by recent work by Uddling et al. (2007).

The addition of a species parameter to the model reduced the residual variance (from 11 to $4 \%$ ) because most of the species-specific models diverged substantially at high SPAD units (see Appendix $2^{1}$ ). The differences observed between species may be related to differences in the distribution of chlorophyll in tree leaves as a result of the structural organization of chlorophyll molecules in chloroplasts, chloroplasts in cells, and cells in leaves (Fukshansky et al., 1993). It is generally accepted that with increasing heterogeneity of chlorophyll distribution inside a leaf, the absorption of a given amount of chlorophyll decreases (Uddling et al., 2007) and the relationship between SPAD and chlorophyll content deviates more from linearity. Another potential source of heterogeneity in the chlorophyll distribution may be the veins and veinules network (McClendon and Fukshansky, 1990). Even though we were careful to avoid veins when measuring SPAD, it remains possible that some measurements were biased because they were made along veins, reinforcing the curvilinear shape of the calibration curve. Alternatively, it has been sug- gested that differences in LMA (Leaf Mass per Area), among or within species, may lead to different calibration curves (Thompson et al., 1996) through different degrees of mutual shading among chloroplasts. Assuming that higher LMA is related to a greater leaf thickness, mutual chloroplast shading may be avoided in thicker leaves (Hikosaka, 2004) even if our data suggest no effect of LMA per se (we found no relationship between alpha-beta and LMA, results not shown). All in all, interspecific differences in the homographic model were clear but explain a relatively small proportion of variation in chlorophyll content in our data set (less than $7 \%$ ).

Despite the increasing frequency with which leaf functional trait studies are employing optical meters to estimate chlorophyll content, few studies have reported results on the relative statistical performance of different models to describe the SPAD-chlorophyll relationships. Tropical tree species appear to represent the broadest range of SPAD and chlorophyll values reported in the literature, and our results demonstrated that foliar chlorophyll of tropical trees could be reliably estimated using the SPAD-502 meter. The utility of the general homographic model (Fig. 1) clearly outweighs limitations due to the loss of model accuracy. The SPAD-502 meter provides a simple, non-destructive method for estimating foliar chlorophyll 
that quickly reports a large number of readings, thus paving the road for immediate assessment of physiological variables (Hawkins et al., 2009). In this way, it should be possible to use the SPAD-502 as a tool for a variety of research and management applications, including the assessment of physiological changes over time, the assessment of relative health status or to delineate the effects of management and logging practices on the photosynthetic performance.

Acknowledgements: The authors are indebted to Pascal Imbert, Jean-Yves Goret, Saintano Dufort, Marcel Blaize, Jean-Louis De Kerpeztron and Henry Grootfaam (UMR Ecofog, Kourou) for their help throughout the experiment. E. Pinkard graciously provided the raw data from her published study.

\section{REFERENCES}

Baraloto C., Goldberg D.E., and Bonal D., 2005. Performance trade-offs among tropical tree seedlings in contrasting microhabitats. Ecol. 86: 2461-2472.

Campbell R.J., Mobley K.N., Marini R.P., and Pfeiffer D.G., 1990. Growing conditions alter the relationship between SPAD-502 values and apple leaf chlorophyll. Hortsci. 25: 330-331.

Coste S., Roggy J.-C., Imbert P., Born C., Bonal D., and Dreyer E., 2005. Leaf photosynthetic traits of 14 tropical rain forest species in relation to leaf nitrogen concentration and shade tolerance. Tree Physiol. 25: $1127-1137$.

Efron B. and Tibshirani R.J., 1993. An introduction to the bootstrap, Chapman-Hall, London, $456 \mathrm{p}$.

Fukshansky, Martinez A., Remisowsky V., McClendon J., Ritterbusch A., Richter T., and Mohr H., 1993. Absorption spectra of leaves corrected for scattering and distributional error: a radiative transfer and absorption statistics treatment. Photochem. Photobiol. 57: 538-555.

Hawkins T.S., Gardiner E.S., and Comer G.S., 2009. Modeling the relationship between extractable chlorophyll and SPAD-502 readings for endangered plant species research. J. Nat. Conserv. 17: 123-127.

Hikosaka K., 2004. Interspecific difference in the photosynthesisnitrogen relationship: patterns, physiological causes, and ecological importance. J. Plant Res. 117: 481-494.

Hiscox J. and Israelstam G., 1979. A method for the extraction of chlorophyll from leaf tissue without maceration. Can. J. Bot. 57: 13321334.
Manetas Y., Grammatikopoulos G., and Kyparissis A., 1998. The use of the portable, non-destructive, SPAD-502 (Minolta) chlorophyll meter with leaves of varying trichome density and anthocyanin content. J. Plant Physiol. 153: 513-516.

Marenco R.A., Antezana-Vera S.A., and Nascimento H.C.S., 2009. Relationship between specific leaf area, leaf thickness, leaf water content and SPAD-502 readings in six Amazonian tree species. Photosynth. 47: 184-190.

Markwell J., Osterman J., and Mitchell J., 1995. Calibration of the Minolta SPAD-502 leaf chlorophyll meter. Photosynth. Res. 46: 467472.

McClendon J.H. and Fukshansky L., 1990. On the interpretation of absorption spectra of leaves I. The introduction and the correction of leaf spectra for surface reflection. Photochem. Photobiol. 51: 203210.

Monje O.A. and Bugbee B., 1992. Inherent limitations of nondestructive chlorophyll meters - a comparison of 2 types of meters. Hortscience 27: 69-71.

Murillo-Amador B., Avila-Serrano N.Y., Garcia-Hernandez J.L., LopezAguilar R., Troyo-Dieguez E., and Kaya C., 2004. Relationship between a nondestructive and an extraction method for measuring chlorophyll contents in cowpea leaves. J. Plant Nutr. Soil Sc. 167: 363-364.

Pinkard E.A., Patel V., and Mohammed C., 2006. Chlorophyll and nitrogen determination for plantation-grown Eucalyptus nitens and $E$. globulus using a non-destructive meter. For. Ecol. Manage. 223: 211217.

Richardson A.D., Duigan S.P., and Berlyn G.P., 2002. An evaluation of noninvasive methods to estimate foliar chlorophyll content. New Phytol. 153: 185-194.

Rozendaal D.M.A., Hurtado V.H., and Poorter L., 2006. Plasticity in leaf traits of 38 tropical tree species in response to light; relationships with light demand and adult stature. Funct. Ecol. 20: 207-216.

Schaper H. and Chacko E.K., 1991. Relation between extractable chlorophyll and portable chlorophyll meter readings in leaves of eight tropical and subtropical fruit tree species. J. Plant Physiol. 138: 674-677.

Thompson J.A., Schweitzer L.E., and Nelson R.L., 1996. Association of specific leaf weight, an estimate of chlorophyll, and chlorophyll concentration with apparent photosynthesis in soybean. Photosynth. Res. 49: $1-10$.

Uddling J., Gelang-Alfredsson J., Piikki K., and Pleijel H., 2007. Evaluating the relationship between leaf chlorophyll concentration and SPAD-502 chlorophyll meter readings. Photosynth. Res. 91: $37-46$. 